PhD Neven TRAJčEVSKI, Ass. Professor (“Goce Delčev” University, Military academy, Skopje, Macedonia); PhD Mite TOMOV, Ass. Professor ("Ss. Cyril and Methodius” University in Skopje, Faculty of Mechanical Engineering - Skopje, Macedonia); PhD Mikolaj KUZINOVSKI, Professor ("Ss. Cyril and Methodius" University in Skopje, Faculty of Mechanical Engineering - Skopje, Macedonia); PhD Piotr CICHOSZ, Professor (Institute of Production Engineering and Automation of the Wroclaw University of Technology, Poland):

\title{
INTRODUCING OF MEASUREMENT UNCERTAINTY IN EMPIRICAL POWER MODELS OF PHYSICAL PHENOMENA DURING MACHINING PROCESSES
}

\begin{abstract}
$\underline{\text { Abstract }}$
This paper propose determining the measurement uncertainty of the coefficient and the exponents of an empirical predictive power model in the metal cutting machining processes. Uncertainty of the coefficient and exponents represent model's capability and quality for further use. For empirical model ling it is used Design of experiments (DOE) method.
\end{abstract}

Keywords: empirical, physical, modelling, measurement, uncertainty, cutting force, temperature, machining, Turing 


\title{
INTRODUCING OF MEASUREMENT UNCERTAINTY IN EMPIRICAL POWER MODELS OF PHYSICAL PHENOMENA DURING MACHINING PROCESSES
}

\author{
Neven TRAJČEVSKI ${ }^{1}$, Mite TOMOV' ${ }^{2}$, Mikolaj KUZINOVSKI ${ }^{2}$, \\ Piotr CICHOSZ ${ }^{3}$
}

\section{INTRODUCTION}

Research of the physical phenomena during the cutting processes by machining (cutting forces, temperature, stresses, strains, wear etc.) has significant advances in the last period. Often such fundamental quantities are described by process models in order to be useful in the industry and to be correlated with the product development and the product quality. There are many methods and approaches to achieve this task and they can result with analytical, numerical, empirical, artificial-intelligence or hybrid models. An overview for the achievements in this field is given in [1]. The empirical modeling of these quantities is based on experimental measurements and it is influenced with the errors which arise in this process. That is why, recently, a significant attention is paid for measurement uncertainty determination during the measurement of the quantities which are used further for the empirical modeling. It is an additional task, which was often neglected by many researchers. Besides representing the reliability of the measured value, measurement uncertainty is depicturing the sources and the size of influencing errors in this process. The process of determination of the measuring uncertainty budget gives possibility and imposes further work in the reduction of the error sources. Examples of measurement uncertainty of cutting force meas-

\footnotetext{
1 "Goce Delčev" University, Military academy, ul. Vasko Karangjeleski bb, 1000 - Skopje, Macedonia, e-mail: neven.trajchevski@gmail.com

2 "Cyril and Methodius" University in Skopje, Macedonia, Faculty of Mechanical Engineering, email: mitetomov@mf.edu.mk; mikolaj@mf.edu.mk; mikolaj.kuzinovski@yahoo.com

${ }^{3}$ Institute of Production Engineering and Automation of the Wroclaw University of Technology, Poland, e-mail: piotr.cichosz@pwr.edu.pl
} 
urements are given in $[2,3]$. These works account both, measurement equipment and cutting process errors. Even, given are examples of proposed models to predict the measurement uncertainty related to the cutting process parameters. However, if we return to the final interest, the empirical model of the physical phenomenon, we must stress that adoption of the models by industry significantly depends on the capability and reliability of the model to predict machining performances. We consider the power models like appropriate way of presenting the physical meaning of the investigated phenomenon, where the exponents are showing the size and the trend of the influencing parameter on the fundamental quantity. In order to have measure of the quality of the empirical power model, we propose that constants and the exponents of the power model should be presented by measurement uncertainty parameters. To achieve that, we suggest that during the process of determination of the constants and the exponents of the empirical power model, we should include the measurement uncertainty of all single measurements. The process of creation of the empirical power model includes many single measurements in the domain of the varied process parameters. In this way, uncertainty parameters of the constant and the exponents of the empirical power model will contain the combined measurement uncertainty of all single measurements. In our example of empirical modeling design of experiments (DOE) method by using two-level factorial design has been applied [4].

\section{ABOUT THE UNCERTAINTY OF SINGLE MEASUREMENT}

Many contributors are included in the uncertainty budget of single measurement. Based on examples from our previous work $[3,5]$ we can name the most significant.

For the cutting force measurement: calibration of the measuring system, environment temperature, acquisition circuit resolution, measurement cell output voltage averaging, cutting process parameters (cutting depth, feed rate and cutting speed), where in the calibration of the measuring system are considered rotational effect, nonlinearity of the calibration line and the calibration load itself. Calibration of the measuring system has been made by means of weight load and respectively, contributors which outcome by using of that method are gravitation acceleration, density of the weights material, atmospheric density and weights mass.

For the average temperature measurement: thermo-voltage value averaging, thermoelectric characteristic interpolation, temperature variation during experimental determination of thermoelectric characteristic, error in thermo-voltage measuring during experimental determination of the thermoelectric characteristic, amplifier output voltage, acquisition circuit resolution, amplification coefficient, error in amplification coefficient from temperature variation influence on optically-coupled isolation amplifier and cutting process parameters (cutting depth, feed rate and cutting speed).

From the papers [2] and [3], it can be seen that significant contribution to the measurement uncertainty of single cutting force is the cutting process itself, or the 
machining parameters, although in many previous works only the contribution of the measuring equipment is accounted. This is especially significant for the topic in question. In particular, empirical modeling is based on measured values of the fundamental variables for certain machining parameters. When there is deviation of the programmed machining parameters while measuring, as result of machine inaccuracy, then machining parameters domain which is taken in consideration for the empirical modeling has deviation also. The only appropriate way to represent this error is to be included in the measuring uncertainty. The size of the contribution of the machining process in the measuring uncertainty budget can vary significantly from one to another single measurement. It can be around $40 \%$ like in the example in [2] or even bigger, around $90 \%$, like in the example [3], when the absolute contribution from the measuring equipment is decreased. Size of the particular contribution from the measuring system depends from the applied measurement equipment, machine and methodology used.

It is very interesting to compare the relative expanded uncertainty for one single measurement from the previous examples. For the coverage factor $k=2$, they are $3,2 \%$ for measured absolute value of tangential cutting force component of 743,3 $\mathrm{N}$ and $7,7 \%$ for measured absolute value of tangential cutting force component of $278,8 \mathrm{~N}$. Besides all influencing factors mentioned above we can expect that they will depend also on the absolute value of the measured quantity.

\section{UNCERTAINTY OF THE COEFFICIENT AND THE EXPONENTS OF THE POWER MODEL}

The general form of the modeled power function is given by (1),

$$
Y=\mathrm{C} \cdot \tau_{1}^{p 1} \cdot \tau_{2}^{p 2} \cdot \tau_{3}^{p 3} \cdot \tau_{4}^{p 4}
$$

where, $Y$ is investigated physical phenomenon (one of the fundamental quantities, for example it can be $F_{z}$ - tangential cutting force), C-constant of the empirical model, $\tau_{i}$, $i=1 . .4$ - cutting process parameters, (for example: $v$-cutting speed, $a$-cutting dept, $f$ feed rate, $r_{\varepsilon}$ - cutting tool radius). Empirical modeling is performed according to DOE based full factorial two-level experimental plan given in table 1.

In order to simplify the mathematical calculations, we take the natural logarithm from both sides and we receive a linear model given by (2). In table 1 factor values coding is used according to (3) in order to operate further with simple coded values [6].

$$
L_{Y}=b_{0} x_{0}+b_{1} x_{1}+b_{2} x_{2}+b_{3} x_{3}+b_{4} x_{4}
$$


where $x_{0}=1, x_{i}=\ln \tau_{i}, L_{Y}=\ln Y, i=0 . .4, b_{i}$ - coefficients of the linearized model.

Table 1. Two-level full factorial experimental plan

\begin{tabular}{|c|c|c|c|c|c|c|c|c|c|}
\hline \multirow{3}{*}{$\begin{array}{l}\text { No } \\
(k)\end{array}$} & \multirow{3}{*}{$\begin{array}{l}\text { Row } \\
\text { code }\end{array}$} & \multicolumn{5}{|c|}{ Coded plan matrix } & \multirow{3}{*}{$\begin{array}{c}\begin{array}{c}\text { Result } \\
\text { (Measured } \\
\text { value) }\end{array} \\
Y_{k} \\
{[\mathrm{~N}]}\end{array}$} & \multirow{3}{*}{$\begin{array}{c}\begin{array}{c}\text { Standard } \\
\text { uncertainty }\end{array} \\
\delta Y_{k} \\
{[\mathrm{~N}]}\end{array}$} & \multirow{3}{*}{$\frac{\ln Y_{h}}{L_{Y k}}$} \\
\hline & & \multirow[b]{2}{*}{$x_{0}$} & \multirow[b]{2}{*}{$x_{1}$} & \multirow[b]{2}{*}{$x_{2}$} & \multirow[b]{2}{*}{$x_{3}$} & \multirow[b]{2}{*}{$x_{4}$} & & & \\
\hline & & & & & & & & & \\
\hline 1 & 2 & 3 & 4 & 5 & 6 & 7 & 8 & 9 & 10 \\
\hline 1. & (1) & 1 & -1 & -1 & -1 & -1 & $Y_{1}$ & $\delta Y_{1}$ & $L_{Y 1}$ \\
\hline 2. & $a$ & 1 & 1 & -1 & -1 & -1 & $Y_{2}$ & $\delta Y_{2}$ & $L_{Y 2}$ \\
\hline 3. & $b$ & 1 & -1 & 1 & -1 & -1 & $Y_{3}$ & $\delta Y_{3}$ & $L_{Y 3}$ \\
\hline 4. & $a b$ & 1 & 1 & 1 & -1 & -1 & $Y_{4}$ & $\delta Y_{4}$ & $L_{Y 4}$ \\
\hline 5. & $c$ & 1 & -1 & -1 & 1 & -1 & $Y_{5}$ & $\delta Y_{5}$ & $L_{Y 5}$ \\
\hline 6. & $a c$ & 1 & 1 & -1 & 1 & -1 & $Y_{6}$ & $\delta Y_{6}$ & $L_{Y 6}$ \\
\hline 7. & $b c$ & 1 & -1 & 1 & 1 & -1 & $Y_{7}$ & $\delta Y_{7}$ & $L_{Y 7}$ \\
\hline 8. & $a b c$ & 1 & 1 & 1 & 1 & -1 & $Y_{8}$ & $\delta Y_{8}$ & $L_{Y 8}$ \\
\hline 9. & $d$ & 1 & -1 & -1 & -1 & 1 & $Y_{9}$ & $\delta Y_{9}$ & $L_{Y 9}$ \\
\hline 10. & $a d$ & 1 & 1 & -1 & -1 & 1 & $Y_{10}$ & $\delta Y_{10}$ & $L_{Y 10}$ \\
\hline 11. & $\overline{b d}$ & 1 & -1 & 1 & -1 & 1 & $Y_{11}$ & $\delta Y_{11}$ & $L_{Y 11}$ \\
\hline 12. & $a b d$ & 1 & 1 & 1 & -1 & 1 & $Y_{12}$ & $\delta Y_{12}$ & $L_{Y 12}$ \\
\hline 13. & $c d$ & 1 & -1 & -1 & 1 & 1 & $Y_{13}$ & $\delta Y_{13}$ & $L_{Y 13}$ \\
\hline 14. & $a c d$ & 1 & 1 & -1 & 1 & 1 & $Y_{14}$ & $\delta Y_{14}$ & $L_{Y 14}$ \\
\hline 15. & $b c d$ & 1 & -1 & 1 & 1 & 1 & $Y_{15}$ & $\delta Y_{15}$ & $L_{Y 15}$ \\
\hline 16. & $a b c d$ & 1 & 1 & 1 & 1 & 1 & $Y_{16}$ & $\delta Y_{16}$ & $L_{Y 16}$ \\
\hline 17. & 0 & 1 & 0 & 0 & 0 & 0 & $Y_{17}$ & $\delta Y_{17}$ & $L_{Y 17}$ \\
\hline 18. & 0 & 1 & 0 & 0 & 0 & 0 & $Y_{18}$ & $\delta Y_{18}$ & $L_{Y 18}$ \\
\hline 19. & 0 & 1 & 0 & 0 & 0 & 0 & $Y_{19}$ & $\delta Y_{19}$ & $L_{Y 19}$ \\
\hline 20. & 0 & 1 & 0 & 0 & 0 & 0 & $Y_{20}$ & $\delta Y_{20}$ & $L_{Y 20}$ \\
\hline
\end{tabular}

$$
\begin{gathered}
x_{i k}=1+2 \cdot\left(\frac{\ln \tau_{i j}-\ln \tau_{i 1}}{\ln \tau_{i 1}-\ln \tau_{i 3}}\right) i=1,2,3,4 ; \quad j=1,2,3 ; \quad k=1,2, . ., 20 . \\
j=1 \text { for } \tau_{i} \text { - factor high level }
\end{gathered}
$$

where:

$$
\begin{aligned}
& j=2 \text { for } \tau_{i} \text {-factor midlelevel } \\
& j=3 \text { for } \tau_{i} \text { - factor low level }
\end{aligned}
$$


Solution for the coefficients $b_{i}$ is given by the matrix $\mathbf{B}$ (4), where the procedure of last square method in matrix form is applied,

$$
\mathbf{B}=\left(\mathbf{X}^{\prime} \mathbf{X}\right)^{-1} \mathbf{X}^{\prime} \mathbf{L}_{\mathbf{Y}}
$$

where $\mathbf{X}$ is coded plan matrix (columns 3 to 7 in table 1 ), $\mathbf{L}_{\mathbf{Y}}$ is matrix of logarithmic values of $\mathbf{Y}$ (column 10 in table 1).

We propose to the explicit formulas of the coefficients $b_{i}(5)$ to be added already determined parameter of standard uncertainty for each single measurement, $\delta Y_{k}$, and

$$
\begin{aligned}
& b_{0}=\frac{1}{20}\left(L_{Y 1}+L_{Y 2}+L_{Y 3}+\cdots+L_{Y 20}\right) \\
& b_{1}=\frac{1}{16}\left(-L_{Y 1}+L_{Y 2}-L_{Y 3}+\cdots+L_{Y 16}\right) \\
& \vdots \\
& b_{4}=\frac{1}{16}\left(-L_{Y 1}-L_{Y 2}-L_{Y 3}-\cdots+L_{Y 16}\right)
\end{aligned}
$$

the new expression for $b_{i}$ to be (6):

$$
\begin{aligned}
& b_{0}=\frac{1}{20}\left[\ln \left(\mathrm{Y}_{1}+\delta Y_{1}\right)+\ln \left(\mathrm{Y}_{2}+\delta Y_{2}\right)+\ln \left(\mathrm{Y}_{3}+\delta Y_{3}\right)+\cdots+\ln \left(\mathrm{Y}_{20}+\delta Y_{20}\right)\right] \\
& \vdots \\
& b_{4}=\frac{1}{16}\left[-\ln \left(\mathrm{Y}_{1}+\delta Y_{1}\right)-\ln \left(\mathrm{Y}_{2}+\delta Y_{2}\right)-\ln \left(\mathrm{Y}_{3}+\delta Y_{3}\right)-\cdots+\ln \left(\mathrm{Y}_{16}+\delta Y_{16}\right)\right)
\end{aligned}
$$

Further the final decoded expressions for the coefficient and the exponents of the empirical model (1) are given by (7), where $b_{i}$ combines all the standard uncertainties $\delta Y_{1}$ to $\delta Y_{20}$ for every single measurement:

$$
\begin{aligned}
& C=e^{b_{0}+\sum_{i=1}^{4} a_{i} b_{i}} \\
& p_{i}=A_{i} b_{i}
\end{aligned}
$$

where $A_{i}=2 / \ln \left(\tau_{i 1} / \tau_{i 3}\right), \quad a_{i}=1-A_{i} \ln \tau_{i 1}, b_{i}$ is given by (6), $i=1,2,3,4$. 
The final decoded expressions (7) are complex and contain many terms but now we can use them for propagation of the coefficient and the exponents of the empirical model (1) and their combined standard uncertainties and further the expanded uncertainty $U C$ and $U p_{i}$.

By using the gained results for the uncertainty of the coefficient and the exponents, we can write the predictive power empirical model in the following form (8):

$$
Y=(C \pm U C) \cdot \tau_{1}^{p_{1} \pm U p_{1}} \cdot \tau_{2}^{p_{2} \pm U p_{2}} \cdot \tau_{3}^{p_{3} \pm U p_{3}} \cdot \tau_{4}^{p_{4} \pm U p_{4}}
$$

Only now we can make estimations of the reliability of the values of the coefficient and the exponents of the power empirical model, and about their influence and trend on the investigated physical phenomenon.

\section{CONCLUSIONS}

This paper gives the procedure of determining the measurement uncertainty of the coefficient and the exponents of an empirical predictive power model in the metal cutting machining processes. When the DOE method and the experimental measuring in many points of the experimental plan are used, measuring uncertainty of every single measurement is combined in the measurement uncertainty of the coefficient and the exponents with a complex mathematical expression. Uncertainty parameters included in the exponents of the power model represent its reliability and its value for application in the industry can be estimated. The complexity of the expression for propagation of the coefficient and the exponents and their uncertainty shows the importance of the efforts for decreasing of error contributions. Additional influence factor is the number of terms in the expressions for determining of the combined uncertainty which will depend on the experimental plan type. Further works should present certain examples in this form and show how different experimental plans affect the value of the measurement uncertainty.

\section{REFERENCES}

[1] ARRAZOLA P.J., ÖZEL T., UMBRELLO D., DAVIES M., JAWAHIR I.S., Recent advances in modelling of metal machining processes. CIRP Annals - Manufacturing Technology, Volume 62, Issue 2, pages $695-718,2013$.

[2] AXINTE D.A., BELLUCO W., DE CHIFFRE L., Evaluation of cutting force uncertainty components in turning. International Journal of Machine Tools \& Manufacture 41, Elsevier Ltd, pages 719 $-730,2001$.

[3] KUZINOVSKI M., TRAJČEVSKI N., TOMOV M., CICHOSZ P., SKOWRONEK H., An approach for measurement uncertainty evaluation of cutting force in machining by turning. Obróbka skrawa- 
niem - Synergia nauki z przemysłem, VIII Szkoła Obróbki Skrawaniem, Międzyzdroje - Szczecin, pages $55-62,2014$.

[4] ISO, Statistics - Vocabulary and symbols - Part 3: Design of experiments, International standard, ISO 3534-3:2013, Third edition, International Organization for Standardization, 2013.

[5] TRAJČEVSKI N., Development of methodology to assess the quality of experimental results during research of physical phenomena in the process of machining by material removal. $\mathrm{PhD}$ thesis, University "Ss. Cyril and Methodius", Faculty of Mechanical Engineering, Skopje, Macedonia, 2013.

[6] KOVAČ P., Modeliranje procesa obrade, Faktorni planovi eksperimenta. Fakultet tehničkih nauka Novi Sad, Srbija, 2006. 